\title{
Leishmaniose Tegumentar Americana (LTA) em Mato Grosso do Sul
}

\author{
Roxana Maria de Guadalupe Bettini Yarzon'1, Maria Elizabeth Cavalheiros Dorval², Hilda \\ Guimarães de Freitas ${ }^{1}$ e Elisa Teruya Oshiro²
}

Em Mato Grosso do Sul, a LTA é endêmica e a despeito da ampla distribuição e do crescente número de casos, pouco se conhece a respeito de várias características clínicas, biológicas e ecoepidemiológicas da doença no Estado. Apesar da existência do trabalho de Nunes et al., 1995 que identificou $L$. braziliensis em uma área de ocorrência da parasitose, desconhece-se a real etiologia dos casos de LTA em Mato Grosso do Sul.

A média anual de casos de LTA notificados no Sistema Nacional de Agravos de Notificação (SINAN) no período de 1999 a 2002 foi de 378,2, com maior número de casos (465)

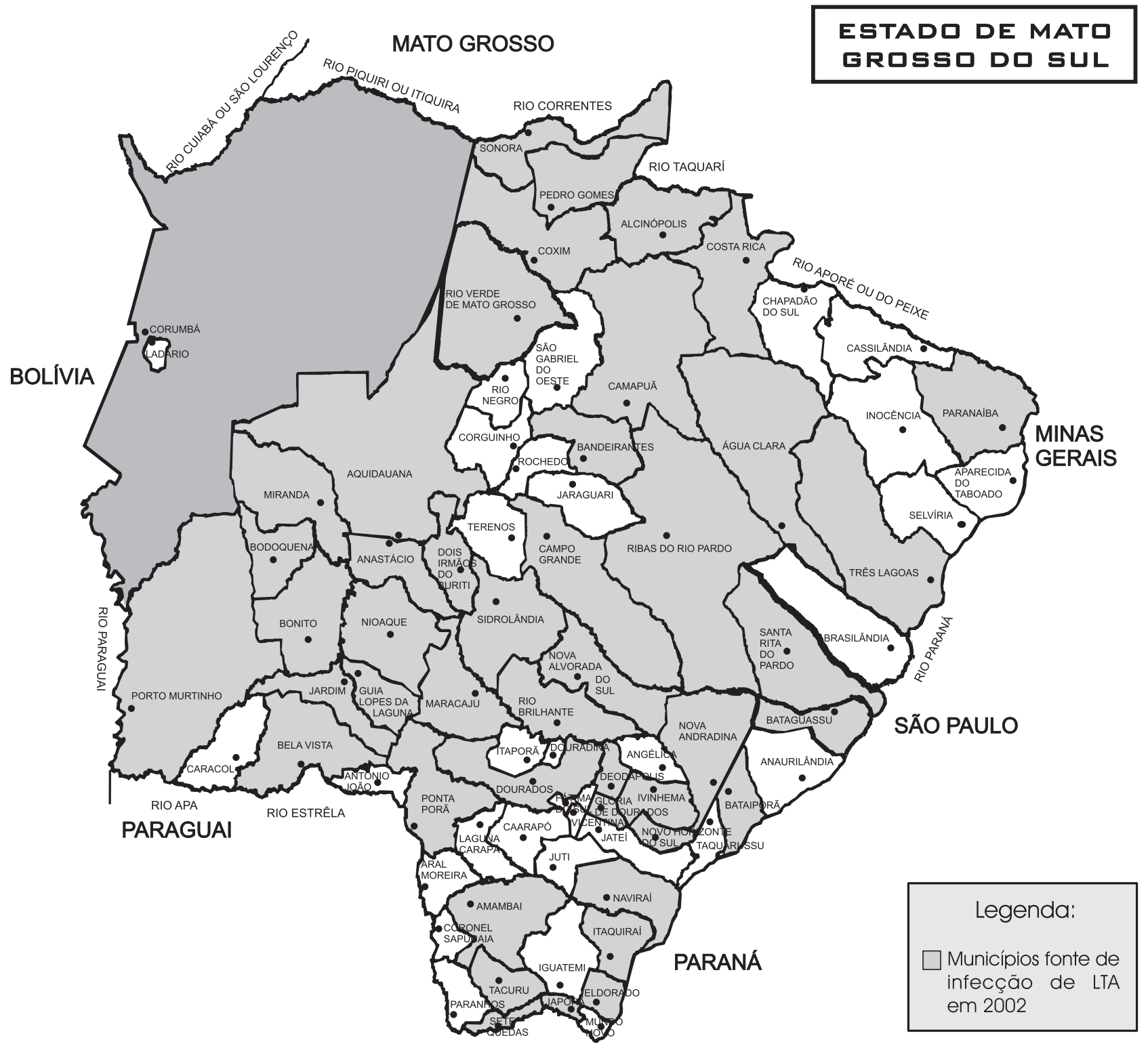

FONTE: SINAN/SES/MS

Figura 1 - Municípios de Mato Grosso do Sul, fontes de infecção de Leishmaniose Tegumentar, 2002

1. Coordenadoria de Vigilância Epidemiológica e Promoção à Saúde, Secretaria de Estado de Saúde de Mato Grosso do Sul. 2. Laboratório de Parasitologia, Departamento de Patologia, Universidade Federal de Mato Grosso do Sul. 
em 2001. Já em 2002, ocorrreram 350 casos da doença em 58 municípios, devendo-se, portanto, reconhecer a importância dessa parasitose no Estado.

Em Campo Grande, onde a população urbana é predominante, o número de casos (5) considerados infectados nesta cidade, poderia sugerir a ocorrência de transmissão urbana, embora permita supor também, confusão na interpretação do local de diagnóstico e provável local de infecção no momento da notificação, o que dificulta qualquer avaliação uma vez que, são escassos os estudos sistematizados sobre vetores, reservatórios e alterações ambientais, os quais poderiam ser fatores determinantes de expansão e talvez de urbanização da parasitose em MS. Tal observação requer, portanto, maior rigor na investigação epidemiológica.

Os casos ocorreram em ambos os sexos, com predomínio do sexo masculino $(66,0 \%)$. A ocorrência da doença em menores de 14 anos $(7,8 \%)$ e em mulheres $(33,5 \%)$ poderia sugerir a adaptação peridomiciliar de vetores, porém, pode ser explicada pelas precárias condições de moradia, em geral muito próximas às matas e também, pelo hábito de afazeres domésticos e ou de lazer fora das habitações, o que poderia expô-los ao risco de aquisição do parasita.

Merece destaque o fato de que, a despeito do incremento do número de casos e de municípios com a doença, os serviços de diagnóstico mostram deficiências, evidenciadas pelo número de realizações da intradermoreação de Montenegro (163) e da pesquisa direta do parasito (196), que, quando positiva, confirma 0 diagnóstico de LTA, principalmente pelo fato da forma clínica mais comum ser a cutânea $(84,1 \%)$.
Como não se tem registrado o tempo de evolução da lesão à época do diagnóstico e nem o conhecimento sobre a existência de portadores da forma anérgica de ITA no Estado, questiona-se o número de reações negativas ao teste de Montenegro (14,8\%), que é positivo em cerca de $95 \%$ dos casos e embora não marcador de doença, é altamente sensível e específico (Cruz, AzeredoCoutinho 2001). Acresce-se a isso a ausência do teste em $41,4 \%$, o que impõe a necessidade da implantação de serviços de referência, não só para a capacitação, mas também para a padronização de condutas dos profissionais quanto ao diagnóstico e tratamento precoces, minimizando as sequielas do parasitismo.

Além disso, faz-se necessário o isolamento e a caracterização das espécies que ocorrem no Estado, o que subsidiará o planejamento de ações efetivas de controle de acordo com as características epidemiológicas do parasito envolvido.

\section{REFERÊNCIAS BIBLIOGRÁFICAS}

Da Cruz AM, Azeredo-Coutinho RB. Leishmaniose Tegumentar Americana. In: Medicina Tropical- abordagem atual das doenças infecciosas e parasitárias. Cultura Médica, 2001.

Miranda C, Massa L, Marques CCA. Análise da ocorrência de leishmaniose tegumentar americana através de imagem obtida por sensoriamento remoto orbital em localidade urbana da região Sudeste do Brtasil. Ver. De Saúde Pública 30: 433-437, 1996.

Nunes VLB, Dorval MEC, Oshiro ET, Noguchi RC, Arão LB, Hans Filho G, Espindola MA, Cristaldo G, Rocha HC, Serafini LN, Santos D. Estudo epidemiológico sobre leishmaniose tegumentar (LT) no município de Corguinho, Mato Grosso do Sul. Estudos na população humana. Rev Soc Bras Med Trop, v.28, n.3, p.185-93, 1995. 